\title{
Development of Duplex PCR Method for Simultaneous Detection of Rabbit (Oryctolagus cuniculus) and Cat (Felis catus) Meats
}

\author{
Yeun Hong • Mi-Ju Kim • Seung-Min Yang • In-Suk Yoo · Hae-Yeong Kim*
}

\section{Duplex PCR을 이용한 토끼(Oryctolagus cuniculus)와 고양이(Felis catus) 육류의 동시 검출법 개발}

홍 연 · 김미주 · 양승민 · 유인숙 · 김해영*

Received: 16 September 2015 / Accepted: 7 October 2015 / Published Online: 31 December 2015

(C) The Korean Society for Applied Biological Chemistry 2015

\begin{abstract}
A duplex polymerase chain reaction (PCR) detection method was developed to authenticate the use of cat and rabbit in food and to prevent unlawful distribution of illegally butchered meat in both domestic and imported food market. Species-specific primers were designed targeting mitochondrial cytochrome $b$ gene. The sizes of PCR products were $191 \mathrm{bp}$ for cat and $101 \mathrm{bp}$ for rabbit, which were relatively small for better application of the detection method on processed foods. Specificities of primers were verified using 21 animal species including cat and rabbit. Limit of detection was examined by serial dilution of the sample DNA and confirmed as $0.005 \mathrm{ng}$ for rabbit and $0.0005 \mathrm{ng}$ for cat using Bioanalyzer. The developed duplex PCR method showed specificity and sensitivity in the identification of two target species.
\end{abstract}

Keywords cat $\cdot$ duplex polymerase chain reaction $\cdot$ food authentication $\cdot$ multiplex polymerase chain reaction $\cdot$ rabbit

Y. Hong $\cdot$ M.-J. Kim $\cdot$ S.-M. Yang $\cdot$ I. Yoo $\cdot$ H.-Y. Kim

Department of Food Science \& Biotechnology and Institute of Life Sciences \& Resources, Kyung Hee University, Yongin 446-701, Republic of Korea

*Corresponding author (H.-Y. Kim: hykim@khu.ac.kr)

This is an Open Access article distributed under the terms of the Creative Commons Attribution Non-Commercial License (http://creativecommons. org/licenses/by-nc/3.0/) which permits unrestricted non-commercial use, distribution, and reproduction in any medium, provided the original work is properly cited.
서 론

근래 불량식품 사례와 종류가 증가하고 있어서 국내외에서 모두 심각한 문제로 관심을 가지고 있다. 이 중 가짜식품(economically motivated adulterated food, EMA food)이란 경제적 이득을 취하 기 위하여 식품의 원료를 속이거나 대체한 경우에 해당한다(Park 등, 2013). 외국의 경우 미국 식품의약품청(Food and Drug Administration. Food safety, Available from: http:/www.fda.gov/ Food/FoodSafety/default.htm. Accessed July 14, 2015)과 영국 식 품기준청(Food Standards Agency. Food Fraud. Available from: http://www.food.gov.uk. Accessed July 14, 2015), 캐나다 국경관 리청(Canada Border Services Agency. CBSA lays charges in immigration fraud case. Available from: http://cbsa-asfc.gc.ca. Accessed July 14, 2015)과 같은 정부기관들에서 가짜 식품을 비 롯한 불량식품의 관리를 강화하고 있고 우리나라도 2010년부터 식품의약품안전처에서 국민들이 즐겨 찾는 다소비식품을 대상으 로 유전자 분석을 활용한 식품원료의 진위 판별법을 마련하고 있 으며(Park 등, 2013; Kim 등, 2014) 식품의약품안전평가원에서 “ 식품 중 사용원료 진위 판별 지침서"로 매년 발간하고 있다.

가공식품은 식품원료의 진위 여부가 가시적이지 않고 가공과 정을 거치면서 식품 원료 고유의 성분이 변하여 이화학적 분석 방법으로 원료의 진위여부를 가리는 것이 불가능한 경우가 많 다. 식품 성분에 비해서 상대적으로 식품 가공과정 중 변화가 적은 $\mathrm{DNA}$ 를 분석하는 방법의 개발이 필요한 이유이다. 그러나 불량식품 판별을 위한 polymerase chain reaction $(\mathrm{PCR})$ 검출 에 사용되는 프라이머를 개발할 때 PCR 반응산물의 크기가 크 면 가공식품 중 일부 분해된 상태로 존재하는 식품원료의 DNA 를 정확하게 검출하는 것이 불가능할 수 있다. 따라서 개발된 판별법을 가공식품의 판별에 적용하려면 PCR 반응산물의 크기 를 약 200 base pair (bp) 또는 그 이하로 조절하여 프라이머 
를 개발해야 한다(Arslan 등, 2006; Haunshi 등, 2009).

미토콘드리아 $\mathrm{DNA}$ 는 진핵세포에 공통적으로 있고 전자전달 계에 필요한 유전자와 이들 효소의 합성에 필요한 $12 \mathrm{~S} \mathrm{rRNA}$ 와 $16 \mathrm{~S} \mathrm{rRNA}, 22 \mathrm{tRNA}$ 도 암호화한다(Attardi와 Schatz, 1988). 동물의 미토콘드리아 DNA는 변이율이 높아서 유사종 간에도 염기서열이 다를 확률이 매우 높은 특징이 있으면서 동 시에 동일한 유전정보를 후대에 물려주기 때문에 서로 다른 종 을 구별해서 검출해야 할 경우에 많이 활용된다(Girish 등, 2004). 또한, 미토콘드리아 DNA는 세포당 copy수가 높아서 시 료 중의 DNA가 분해된 상태이거나 미량으로 혼입된 경우에도 목표로 하는 동물 종의 $\mathrm{DNA}$ 를 $\mathrm{PCR}$ 증폭할 경우 검출 효율이 높다는 장점이 있다(Girish 등, 2004).

불량식품의 판별에 관한 연구들 중 대표적인 동물성 식품 원 료들인 소, 돼지, 양, 닭, 칠면조와 이들 원료들의 유사종들인 가축류와 가금류을 판별하는 연구는 활발하게 진행되었다(Jonker 등, 2008; Ghovvati 등, 2009; Haunshi 등, 2009; Koh 등, 2011; You 등, 2014; Amaral 등, 2015; Li 등, 2015; Safdar 와 Junejo, 2015). 그러나 불량식품의 사례가 일반적으로 식용 으로 인식되는 동물 종에 국한되지 않는 경우도 있어서 불량식 품의 관리대상을 확대하여야 한다. 또, 국가별로 식용과 비식용 의 구분이 서로 달라서 수입식품의 관리를 위해서 다양한 종의 판별법이 필요하다. 토끼의 경우는 정육과 가공을 거친 소시지 와 패티 형태의 식품과 통조림 사료 등이 시중 유통되는 나라 들이 있으며 식당에서 요리를 팔기도 한다. 고양이는 주로 정 육과 식당에서 유통되는 나라들이 있다. 토끼와 고양이의 식품 용도로의 유통은 불법이 아닌 경우가 많고 다만, 이를 가공식 품의 원료로 허가 하는지의 여부는 나라마다 다르다. 2013년 고 양이 고기를 토끼 고기로 둔갑시켜 팔아온 조직이 중국 당국에 적발되었다는 보고가 중국언론과 국내언론(연합뉴스http:// www.yonhapnews.co.kr/international/2013/11/01/0603000000 AKR20131101072000009.HTML), 영국 $\mathrm{BBC}$ 에 보도 되었다. 들 고양이나 애완 고양이를 헐값에 사들여 불법 도살 및 가공 한 뒤 토끼 고기로 속여 식당과 시장에 유통시킨 경우이다. 고 양이는 중국 광둥성에서 일부 식용으로 사용하는데, 이 보도자 료의 경우는 토끼 고기로 속여서 판매한 경우이다. 우리나라도 2014년 보도자료에 따르면(http://imnews.imbc.com/weeklyfull/ weekly01/3396261_12262.html) 지방자치단체가 집계한 전국의 길고양이의 수가 약 100 만 마리로 해마다 증가하고 있어 문제가 되고 있고 현재까지 이를 임의로 죽이는 것은 불법이다. 그러 나 2015년에는 경남 김해의 도축장에서 길고양이 600마리를 불 법 도살하여 건강원에 팔아 넘기다 적발되어 입건된 경우가 발 생했다(국제신문 2015.5.21). 이처럼 불법으로 고양이가 도살 또 는 유통되거나 고양이가 다른 육류를 대체하여 사용되지 않도 록 관리하기 위해 고양이의 신속한 검출법이 필요하다.

본 연구에서는 불량식품 사례가 있는 토끼와 고양이의 동시 분석법을 개발하여 차후 발생할 수 있는 불량식품을 사전에 관
리하는데 활용되도록 하였다. 이를 위해 미토콘드리아의 cytochrome b (cyt b) gene을 대상 유전자로하여 PCR에 필요 한 프라이머를 개발하고 PCR 분석법의 효율을 검토하였다.

\section{재료 및 방법}

시료. 토끼(Oryctolagus cuniculus)와 고양이(Felis catus)는 경기 도 성남시 소재 재래시장에서 육안으로 확인 후 도축한 것을 구입하였고 실험실로 운반 즉시 근육부분을 취하여 흐르는 물 에 충분히 씻은 후 물기를 제거하고 $50 \mathrm{~mL}$ 튜브에 넣어 $-20^{\circ} \mathrm{C}$ 에 보관 하였다. 시료를 사용할 때는 액체질소를 이용하여 막 자사발로 마쇄한 시료를 취하여 $\mathrm{DNA}$ 를 추출하였다. 21종의 동 물 근육 중 토끼와 고양이를 포함한 칠면조, 타조, 닭, 뀡, 오 리, 거위, 소, 양, 돼지, 말, 염소, 개, 사슴, 당나귀 등 16 종은 시중에서 구입하였고, 비둘기, 쥐, 다람쥐, 청설모, 고라니 등 5종 은 서울대학교 수의과대학 야생동물유전자원은행 (www.cgrb.org) 에서 분양 받아 사용하였다.

시료로부터 DNA의 추출. DNeasy Blood \& Tissue Kit (Qiagen, Germany)를 사용하였고 추출법은 키트의 매뉴얼에 따 랐다. 즉, 시료 $25 \mathrm{mg}$ 에 $\mathrm{Kit}$ 에 포함된 $\mathrm{ATL}$ 완충액 $360 \mu \mathrm{L}$ 와 proteinase $\mathrm{K}(20 \mathrm{mg} / \mathrm{mL}) 40 \mu \mathrm{L}$ 를 넣고 $56^{\circ} \mathrm{C}$ 수욕에서 2시간 반응시켰다. RNase A $(100 \mathrm{mg} / \mathrm{mL})$ 를 $4 \mu \mathrm{L}$ 가하고 실온에서 2 분간 반응시킨 후 $\mathrm{Kit}$ 에 포함된 $\mathrm{AL}$ 완충액 $400 \mu \mathrm{L}$ 와 $100 \%$ 에탄올 $400 \mu \mathrm{L}$ 을 가하였다. 이를 스핀 컬럼에 통과시켜 흡착시 킨 후 Kit에 포함된 $\mathrm{AW} 1$ 과 $\mathrm{AW} 2$ 완충액으로 차례로 세척하였 다. 흡착된 $\mathrm{DNA}$ 를 $50 \mu \mathrm{L}$ 의 3차증류수로 용출하여 $\mathrm{UV}$ spectrophotometer (UV-1700, Shimadzu, Japan)를 사용해서 추 출한 $\mathrm{DNA}$ 의 농도를 측정하였고 순도는 $260 / 280 \mathrm{~nm}$ 에서의 흡 광도를 비교하여 1.8-2.0 사이임을 확인하였다.

프라이머 개발. 토끼와 고양이 미토콘드리아의 cyt b gene을 target으로 해서 GenBank 데이터베이스(http://www.ncbi.nlm. nih.gov)와 Clustal Omega alignment분석(http://www.ebi.ac.uk/ Tools/msa/clustalo)을 활용하여 토끼, 고양이의 cyt b gene 염기 서열을 20 종의 동물 염기서열과 비교하였다. Primer Designer 프로그램 버전 3.0 (Scientific and Educational Software, USA) 을 사용하여 종 특이 프라이머를 디자인 하였고 프라이머 합성 은 Bionics (Korea)에 의뢰하였다. PCR 산물의 크기는 가공처 리를 거칠 경우에 대비하여 $200 \mathrm{bp}$ 이하가 되도록 하였고 (Arslan 등, 2006; Haunshi 등, 2009) 동시검출을 위하여 PCR annealing 온도차이는 최소가 되도록 설계하였다. 프라이머의 염 기서열은 Table 1에 정리하였고 target gene의 염기서열 alignment와 디자인한 프라이머의 위치는 Fig. 1에 나타내었다. PCR 반응액 및 조건. PCR 반응액 $25 \mu \mathrm{L}$ 중 $10 \mathrm{X}$ 완충액 (Applied Biosystems Inc., USA)은 $2.5 \mu \mathrm{L}$, 시료 DNA (50 $\mathrm{ng} / \mu \mathrm{L}) 1 \mu \mathrm{L}, 200 \mu \mathrm{M}$ dNTPs, $\mathrm{MgCl}_{2}$ 는 $1.5 \mathrm{mM}$, Ampli Gold

Table 1 Sequences of primers developed for the simultaneous species-specific identification of cat and rabbit

\begin{tabular}{clccc}
\hline Primer name & \multicolumn{1}{c}{ Sequences $\left(5^{\prime} \rightarrow 3^{\prime}\right)$} & Amplicon sizes $(\mathrm{bp})$ & Target genes & Accession No. \\
\hline Cat $\mathrm{F}$ & CTACGGCTCCTACACCTTCT & \multirow{2}{*}{191} & Cytochrome b & AB004238.1 \\
Cat $\mathrm{R}$ & CCCCTCAGATTCATTCTACTAGTTCA & \multirow{2}{*}{101} & Cytochrome b & U07566.1 \\
\hline $\begin{array}{l}\text { Rabbit F } \\
\text { Rabbit } \mathrm{R}\end{array}$ & $\begin{array}{l}\text { CGTCGCAGATCTTCTCACAC } \\
\text { TGGTGGAGAAGTAGAGGACA }\end{array}$ & & & \\
\hline
\end{tabular}


(A)

DUCK
GOORE
TUREY
CHICKEN
PHEASANT
OSRICH
PIGEON
ROREAN
SIBERIAN
RABIT
RAI
DOG
CAT
HORSE
DONKEY
PORK
BEEF
SHEEP
GOAT
DERR
WAIER
DUCK
GOOSE
TUREY
CHICKEN
PHEASANT
OSTRICH
PIGON
KOREAN
SIBERIAN
RABIT
RAT
DOG
CAT
HORSE
DONKEY
PORK
BEEE
SHEEP
GOAT
DEER
WAIER

(B)
Cat F $\rightarrow$ CGAGGCTTCTACTACGGCICCTACCTGTATAAAGAAACTT GAAATACAGGAGTAATCCTA
CGGGGCCTCTACTACGGCTCCTACTTATACAAAGAAACCTGAACACAGGAGTAATCCTC CGCGGCCTATATTATGGTTCGTACCTATATAAAGAAACCTGAAATACAGGAGTAGTCTTA CGCGGCCTCTATTACGGCTCTTACCTGTACAAAGAGACATGAAACACTGGAGTCGICCTA
CGAGGACTCTACTATGGCTCTIACCICTATAAAGAAACCTGAAACACCGGCGITATCCTC CGAGGACTCTACTACGGATCCTACCTCTACAAAGAGACTTGAAACACAGGAGTCGTCCTC

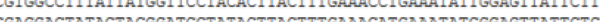
GGGGGAATCTACTATGGATCATACACATACCTAGAGACCTGAAMCATTGGGATCATCCTC GAGGACTATACTAIGGATCCTACACTITCCTAGAAACCTGAAACATTGGGATCAITCTA CGAGGCCTATATTACGGATCCTAIGIATICATAGAAACAIGAAACATTGGAATTGTACTA CGGGGAATATACAACGECTCCTACACCIICHCAGAGACAT GAAACATTGGAATCATACTR CGCGGCCTCTACTACGGCTCTTACACATTCCTAGAGACATGAAACATTGGAATCATCCTA COCGGCCICIACTAIGGCICCIACACATCCIAGAAACAI GAAACAT GGAATTATCCTA CGAGGICTATACTACGGATCCTATATAIICCTAGAAACAIGAAACAIIGGAGTAGICCTA COMGGCCTATACTATGGATCRTATACCTICCTAGAACATGAMCATCGGOTHATCCITC GAAGTCTATATTATGGATCATATACCTITCTAGAAACATGAAACATTGGAGTAATCCTC CGAGGCCTGTACTACGGATCATATACTTTICTA CGAGGCCTATATTATGGATCTTACACTTICCTAGARACAIGAAACATTGGAGTAATTCTC CIGCTCACTCTTATAGCAACTGCCTTCGTAGGITATGTCCTGCCATGAGGACAAATATCG
CTACTCACCCTAATAGCAACTGCCTTCGIAGGATATGTCCTGCCATGAGGACAAATATCA CTTCTCACCCTCATAGCAACAGCCTI CTCCTCACACTCATAGCCACCGCCTITGTGGGCTAIGITCTCCCATGGGGCCAAATATCA CICCTCACACTCATAGCAACCGCCITCGTAGGATAIGTCCTICCATGAGGACAAATATCA

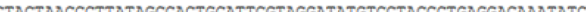
CIACTIACCCCTIATAGCCACTGCATITGIAGGATATGICCTACCCTGAGGACAAATATCA CTATTCGCAGTTATAGCTACAGCATITATAGGCTATGITCTTCCCTGAGGACAGATATCT CTAITCGCAGTAATAGCCACAGCATITAICGGITAIGTCCICCCATGAGGACAAATATCA CTATITGCAGTCATAGCAACTGCATTCATGGGCTATGTACTCCCATGAGGACAAATATCA IIAITCGCAACCAIAGCCACAGCAITCAIGGGCIAIGTACTACCAIGAGGACAAATAICA CTITICACAGTTATAGCTACAGCATTCATGGGCTATGICCTACCATGAGGCCAAATATCC CIITTCACAGTAATAGCCACAGCATTCATAGGCTATGICCTACCATGAGGACAAATATC CTATTTGCGACAATAGCCACAGCATTCATAGGCTATGTCTTACCATGAGGACAAATATC TGCTCGCGACAAIGGCCACAGCATTCATAGGCTATGITTTACCAIGAGGACAAATATCA CTATTTACAGTTATAGCCACAGCATTCGIAGGATATGTCCTACCAT GAGGACAMATAT CTATTCACAGTAATAGCCACAGCATTCGTAGGGTATGTCCTICCATGAGGACAAATATCA

CTGCTCACTCTTATAGCAACTGCCTICGTAGGTTATGTCCTGCCATGAGGACAAATATCG TACTCACCCTAATAGCAACTGCCTTCGTAGGATATGTCCTGCCATGAGGACAAATATCA CTICTCACCCTCATAGCAACAGCCTITGTAGGCTATGTCCTCCCATGGGGACAAATATCA CICCTCACACTCATAGCAACCGCCITCGTAGGATAIGICCTICCAIGAGGACAAATATCA CTACTAACATTAATAGCAACTGCAITTGTAGGTTATGTCCTCCCCTGAGGACAAATATCA CTACTAACCCITATAGCCACTGCATTCGTAGGATAIGTCCTACCCTGAGGACAAATATCA CTATIOCAGIAATAGCCACIGCAITCAIAGGCIAIGIACHTCCAIGAGGACAGATATCA CTATTGGCAGTTATAGCTACAGCATITATAGGCTATGITCTICCCTGAGGACAGATATCT CTATTTGCAGTCATAGCAACTGCATTCATGGGCTATGTACTCCCATGRGGACAMATATCA TTATTCGCAACCATAGCCACAGCATICATGGGCTATGTACTACCATGAGGACAAATATCA ITAITTACAGICATAGCCACAGCTITTAIGGGATACGICCTACCATGAGGCCAAATGTCC CIITTCACAGTTATAGCTACAGCATTCATGGGCTAIGTCCTACCATGAGGCCAAATATCC CTITTCACAGTAATAGCCACAGCATTCATAGGCTATGTCCTACCATGAGGACAAATATCC CIATIIACCGIIATAGCAACAGCCIICATAGGCIACGICCIGCCCIGAGGACAAATATCA CTGCTCACAGTAATAGCCACAGCAITTATAGGATACGTCCTACCATGAGGACARATATCA

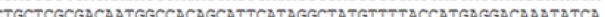
CTATTTACAGTTATAGCCACAGCATICGTAGGATATGTCCTACCATGAGGACAAATATCA CTATTCACAGTAATAGCCACAGCATTCGTAGGGTAIGTCCTICCATGAGGACAAATATCA

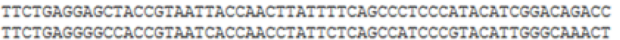
ITCTGAGGGGCCACCGTAATCACCAACCTATICTCAGCCATCCCGTACATTGGGCAAACT TICTGAGGGGCTACCGTCAICACAAACCTATTCTCAGCAATCCCCTACATIGGTCAAACC TITGAGGAGCTACCGICATCACAAACCTAITCTCAGCAAICCCCTACATTGGACAAACC ICTGAGGAGCTACAGTCATTACCAATCTAITCTCAGCIGICCCCTACATTGGCCAAACC TITITGAGGCGCCACAGTCATIACCAATCTAITCTCAGCIGICCCCTACATTGGCCAAACC ITCTGAGGAGCAACAGTIATTACTAATCTICTATCAGCTATCCCTIATATCGGAACAACA TATGGGGAGCAACCGIAATCACTAACCTCCTATCAGCAATCCCATAIAICGGAACAACC ITIGAGGAGCAACTGTAATCACTAATCTICTCTCIGCCAICCCTTATATCGGAACTGIC TCTGAGGAGCAACCGTAATCACTAACCTCCTGTCAGCAATTCCATACATCGGGACFAM TCTGAGGACAACGGTCATTACAAACCTCCTATCAGCARTCCCCTACATCGGTACTACG TCTGAGGAGCAACGGTCATTACAAACCTCCTATCAGCAAICCCCIACATCGGTACTACG TCTGAGGAGCAACAGTCATCACCAACCTCTTATCAGCAATCCCATACATCGGCACAAAT TCTGAGGAGCAACAGTIATTACCAACCTCCITTCAGCAATICCATATATTGGCACAAAC ITTIGAGGGGCAACAGTCAICACTAAICTICTITCAGCAATCCCATATATTGGCACAAAC ITCTGAGGAGCAACAGTCATTACCAACCTICTCTCAGCAAITCCATATATIGGGACAAAC ITCTGAGGAGCAACGGTCATTACTAATCTCCTGTCAGCAATTCCATACGTCGGTACAAAT

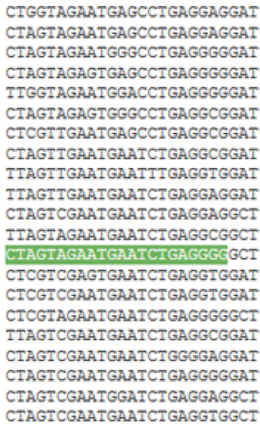

$\leftarrow$ Cat $\mathrm{R}$

Rabbit F $\rightarrow$

CTCTCCCAACTCCTATTCTGAACACTAGTGGCCAACCTCCTCGTCCTAACATGAGTGGGA AGCCAACCTGTCGAACACCCATTCATCATCATCGGGCAACTCGCATCAATTACTTACTTC ACCATCCTC CTCTCCCAACTCCTATTCTGAGIGCTAGTCGCCGACCTCCTCGTCCTAACATGAGTGGGA AGCCAACCCGTCGAACATCCATTCATCATCATCGGCCAACTCGCTTCAATCGCCTACTTC GCTATCCTC CTCTCACAAACCTTATTCTGACTCTTAGTAGCAAACCTCCTCATCCTAACCTGAGTAGGA AGCCAACCAGTAGAACACCCATTCATCATCATTGGCCAARTAGCATCCCTTTCCTACTTC ACTATCTTA CTCTCCCAAACCCTATTCTGACTTCTAGTAGCCAACCTICTTATCCTAACCTGAATCGGA AGCCAACCAGTAGAACACCCCTTCATCATCATTGGCCAAATAGCATCCCTCTCTTACTTC ACCATCCTA CTCTCACAAGCCCTATTCTGGCTAITAGITGCTAACCTICTTAICCTAACCTGAGTAGGA AGCCAACCAGTAGAACACCCATTCATCGTCATTGGCCAAATAGCATCACTTTCATACTTC ACCATTCTA CTCTCTCAITATTATTCTGATTTCTAGIGGCAAACCTACTCAICCTAACATGAATCGGC AGCCAACCAGTAGAACACCCCTICATCATCATCGGCCAAGTAGCTICCTICACTTACTIC CICAICCTA CTAAGCCAATGCTTATTCTGAATCCTAGITGCAGACCTATITACACTAACCTGAATTGGA GGACAACCAGTTGAATATCCTTTTATTATTATTGGACAAGTAGCATCCATCATTTACTTT ACCATCATT CTAAGTCAATGTATGTTCTGAATTTTAGTAGCCGATCTATTGACACTCACCTGAATCGGA GGACAACCAGTGGAACACCCCTTTATCATTATIGGCCAACTAGCATCCATCCTATACTTT TCAATTCTI AITAGTCAAGICCTATTCTGAGITCTCGICGCAGATCTTCTCACAQTCACATGAATCGGA GGCCAACCAGTAGAACACCCGITCATCACCATIGGACAAGTAGCATCTGTCCTCTACTTC ICCACCIIO CTTAGCCAATGCCTATTCTGACTITTAGICGCCGATCTICTCACTTTAACATGAATTGGA GGACAACCAGITGAACACCCITTCATCATTATCGGACAAGTCGCTTCAATCTTATATITC ACCATCTTA CTAAGCCAATGICTATTCTGACTCCTAGIAGCGGATCTCCTAACCCTAACATGAATCGGT GGCCAACCTGTAGAACATCCATTCATCACCATCGGCCAACTAGCCTCCATCCTATATTTC TTAACCCIO GCAGCCAATGCGTATTCTGACTCTTAGIGGCAGACTIACTGACACTAACATGAATCGGC GGACAGCCAGIGGAACACCCATACGTAAITATCGGCCAACTGGCCTCAAICCTCTACTIC TCCCTAATT GTAAGTCAATGGTGITCTGACTCTTAGTAGCAGACTTACTAACACTAACATGAATTGGT GGCCAACCAGTAGAACACCCATACGTAATCATCGGCCAACTGGCCTCAATCCTCTACTIC ICCCTAAT

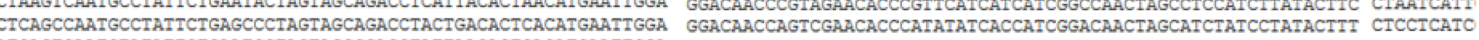
ATCAGICAATGTATATTCTGAATCCTAGTAGCCGACCTATTAACACTCACATGAATIGGA GGCCAGCCAGTTGAACACCCCTACATCAITATTGGACAACTAGCATCTATTATATATTTC CTTATCATT ATCAGCCAATGCATATTCTGAATCCTGGTAGCAGATCTATTAACACTCACATGAATTGGA GGACAGCCAGTCGAACATCCCTACATTATTATIGGACAACTAGCATCTATTATATATTTC CTCATCATT ITCAGCCAATGCCTATTCIGAATCTIAGTAGCAGACCTATTAACACTCACATGAATCGGA GGACAACCAGTTGAATATCCCITIAICATIATTGGACAACTAGCATCTGTCTTATATTIC IICATTATC ITCAGCCAATGCCTATTTTGAATITTAGTAGCAGACTTACTAACATTAACATGAATTGGA GGACAACCAGTCGAATATCCCTTTATCATCATTGGACAACTGGCATCCATCCTGTATTIT CTCATTATC

$\leftarrow$ Rabbit R

Fig. 1 Sequence alignment of cyt $b$ gene and designation of species-specific primers for the simultaneous detection of cat and rabbit.

Taq polymerase (Applied Biosystems Inc.)는 0.2 U, 각 프라이머 는 토끼의 경우는 $400 \mathrm{nM}$, 고양이의 경우는 $320 \mathrm{nM}$ 씩의 최종 농도가 되도록 하였다. $\mathrm{PCR}$ 반응 조건은 $94^{\circ} \mathrm{C}$ 에서 5 분 예비가 열 후 $94^{\circ} \mathrm{C}$ 에서 30 초간 변성, $60^{\circ} \mathrm{C}$ 에서 30 초간 결합, $72^{\circ} \mathrm{C}$ 에 서 30 초간 신장의 과정을 30 회 반복하였고 마지막에 $72^{\circ} \mathrm{C}$ 에서 7분간 처리하였다. 증폭된 PCR 산물은 $3 \%$ agarose gel에서 전 기영동으로 확인하였고, Agilent 2100 bioanalyzer (Agilent Technologies, USA)를 이용해 재확인하였다.

프라이머의 특이성과 분석법의 검출한계. 개발된 프라이머의 특 이성 확인을 위해 토끼 또는 고양이 이외에 19종의 동물을 시 료로 하여 PCR 반응을 통해 프라이머의 특이성을 검토하였다. 개발된 duplex PCR 분석법의 검출한계 측정을 위해 고양이와 토끼의 DNA 각 $50 \mathrm{ng}$ 을 10 배씩 단계별로 $0.00005 \mathrm{ng}$ 까지 희 석하여 사용하였다.

\section{결과 및 고찰}

프라이머의 특이성. 토끼와 고양이의 종 특이 프라이머의 특이 성을 확인하기 위하여 21종의 동물시료로부터 DNA를 추출하 여 single PCR을 수행하였고 그 결과를 Fig. 2에 나타내었다. 고양이와 토끼의 PCR product size는 각각 $191,101 \mathrm{bp}$ 이었고 두 프라이머 모두 다른 동물의 DNA는 증폭시키지 않고 고양 이와 토끼 DNA와만 특이적으로 반응하였다(Fig. 2). Ali 등 (2015)의 연구에서 고양이 검출을 위해 미토콘드리아 cyt b gene을 대상으로 개발한 프라이머를 이용했을 경우 PCR 산물 의 크기는 $172 \mathrm{bp}$ 로 본 연구의 $191 \mathrm{bp}$ 보다 좀 더 작은 크기였 다. Walker 등(2004)은 사람을 비롯해서 말, 개, 고양이, 쥐, 토 끼 등을 대상으로 종 특이 개별 정량 판별법을 개발하였다 (Walker 등, 2004). Yang 등(2014)은 고릴라, 원숭이 등 유사종 


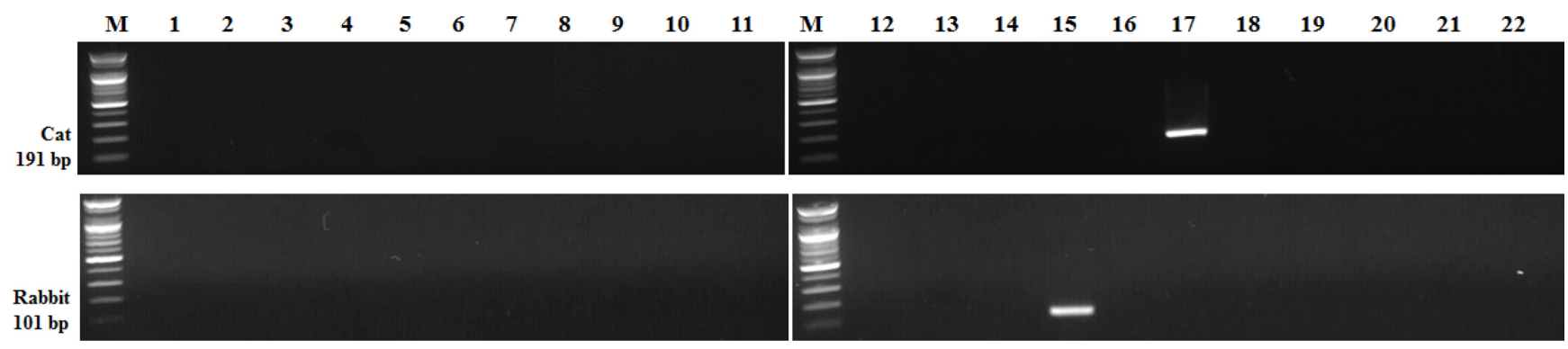

Fig. 2 Specificity of developed primer for the simultaneous detection of cat and rabbit. Lane M: 100 bp DNA ladder, lane 1-21: turkey, ostrich, chicken, pheasant, duck, goose, pigeon, beef, lamb, pork, horse, goat, dog, deer, rabbit, mouse, cat, donkey, Korean squirrel, siberian chipmunk and Korean water deer, lane 22: non-template.

(A)

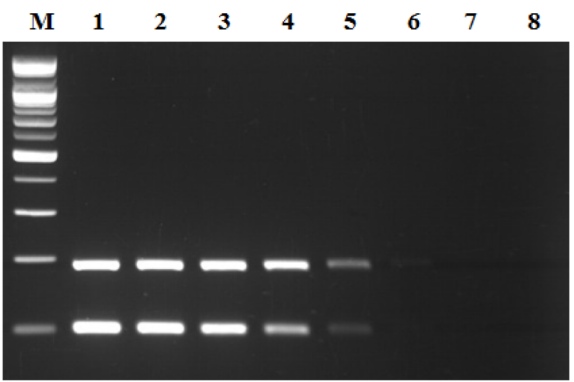

(B)
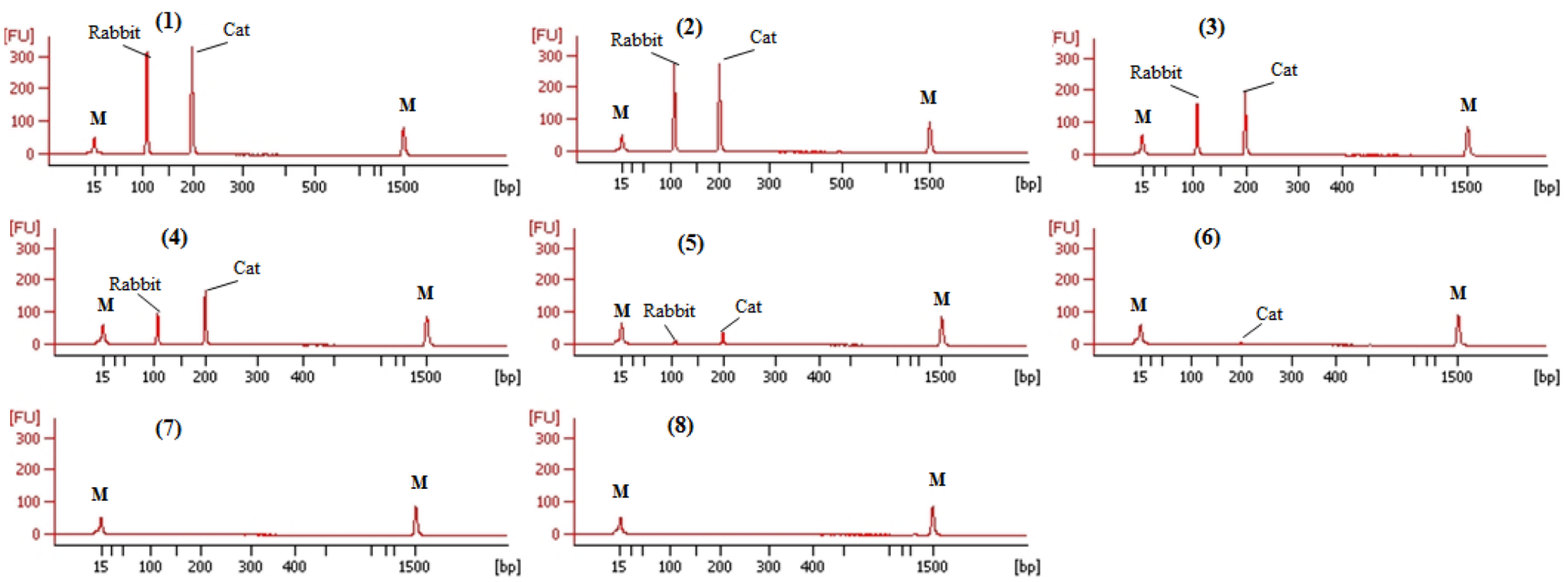

Fig. 3 Sensitivity of developed duplex PCR method for the simultaneous detection of cat and rabbit. (A) Lane M: 100 bp DNA ladder, lane 1-7: 5×101, $10^{0}, 10^{-1}, 10^{-2}, 10^{-3}, 10^{-4}$ and $10^{-5} \mathrm{ng}$ of positive controls, lane 8: non-template. (B) FU: fluorescence, M: alignment marker, (1)-(7): $5 \times 10^{1}, 10^{0}, 10^{-1}$, $10^{-2}, 10^{-3}, 10^{-4}$ and $10^{-5} \mathrm{ng}$ of positive controls, (8): non-template.

과 유사도가 적은 소, 생쥐, 개구리, 은어의 미토콘드리아 DNA 의 종간 및 종내의 차이를 검토하여 특정 종의 미토콘드리아 $\mathrm{DNA}$ 가 다른 종들의 미토콘드리아 DNA와 얼마나 상동성을 보 이는지를 검토하였고 종 특이 판별법에서 가장 중요한 것은 프 라이머의 특이성이라고 보고하였다. 본 연구의 특이성 검증 대 상 21 종에는 식품 원료로 흔히 사용되는 가축류와 가금류가 포 함되어 있었고 국내외에서 불량식품 사례가 보고된 동물 종들 도 포함되었기 때문에 개발된 duplex PCR 법을 사용하면 이들 을 원료로 한 식품 중에 토끼나 고양이의 혼입 여부 또는 고양 이를 토끼로 속여 파는지의 여부를 알아낼 수 있다고 판단된다. 개발된 duplex PCR의 검출한계. Duplex PCR로 토끼와 고양
이를 동시분석 하였을 때 검출한계는 Fig. 3과 같았다. Walker 등(2004)은 사람을 비롯해서 말, 개, 고양이, 쥐, 토끼 등을 대 상으로 종 특이 개별 정량 판별법을 개발하였는데 이들 연구에 서 고양이의 정량검출 한계는 $1 \mathrm{ng}$, 토끼의 경우는 $0.1 \mathrm{ng}$ 이었 다. Multiplex PCR 검출법 개발 연구 중 Koh 등(2011)의 연구 에서 가축류와 가금류 각 동물의 검출한계는 $0.001-1.0 \mathrm{pg}$ 이었 다. Ali 등(2015)이 개발한 고양이를 비롯한 이슬람 금기 동물 의 multiplex PCR법 개발 연구에서 토끼의 multiplex PCR 검 출한계는 $0.1 \mathrm{ng}$ 이었다. 본 연구에서 개발된 duplex PCR의 정 성적 검출한계는 토끼는 $0.005 \mathrm{ng}(5 \mathrm{pg})$, 고양이는 $0.0005 \mathrm{ng}$ $(0.5 \mathrm{pg})$ 이었다. Fig. $3 \mathrm{~A}$ 의 결과를 Bioanalyzer로 분석(Fig. $3 \mathrm{~B})$ 
하여 검출한계를 확인하였다. 이 검출한계는 Walker 등(2004)의 real-time PCR 결과와 Ali 등(2015)의 multiplex PCR 결과보다 민감도가 더 높으며 불량식품 사례가 있는 두 동물을 동시에 판별할 수 있었다.

\section{초 록}

국내 유통 식품 및 수입 식품 중 토끼와 고양이 고기의 혼입 여부를 알아내고 불법 도축된 고양이 고기를 토끼 고기나 다른 고기로 속여 판매하는 것을 방지하기 위해 토끼와 고양이를 동 시에 검출할 수 있는 polymerase chain reaction (PCR) 법을 개발하였다. 토끼와 고양이의 종 특이 프라이머는 미토콘드리아 의 cytochrome b 유전자를 대상으로 하였고 개발된 프라이머를 가공식품에 활용하는 것을 고려하여 PCR 산물의 크기는 토끼 $101 \mathrm{bp}$, 고양이 $191 \mathrm{bp}$ 로 최소화 하였다. 프라이머의 특이성은 총 21 종의 동물을 대상으로 검토하였다. 개발된 검출법의 검출 한계는 시료 $\mathrm{DNA}$ 를 희석하여 PCR과 Bioanalyzer로 확인한 결 과 토끼는 $0.005 \mathrm{ng}$, 고양이는 $0.0005 \mathrm{ng}$ 이었다.

Keywords cat $\cdot$ duplex polymerase chain reaction $\cdot$ food authentication $\cdot$ multiplex polymerase chain reaction $\cdot$ rabbit

감사의 글 This research was supported by a grant (14162MFDS971) from the Ministry of Food and Drug Safety in Korea.

\section{References}

Ali ME, Razzak MA, Hamid SBA, Rahman MM, Amin MA, Rashid NRA et al. (2015) Multiplex PCR assay for the detection of five meat species forbidden in Islamic foods. Food Chem 177, 214-24.

Amaral JS, Santos CG, Melo VS, Costa J, Oliveira MBPP, and Mafra I (2015) Identification of duck, partridge, pheasant quail, chicken and turkey meats by species-specific PCR assays to assess the authenticity of traditional game meat Alheira sausages. Food Control 47, 190-5.
Arslan A, Ilhak OI, and Calicioglu M (2006) Effect of method of cooking on identification of heat processed beef using polymerase chain reaction (PCR) technique. Meat Sci 72, 326-30.

Attardi G and Schatz G (1988) Biogenesis of mitochondria. Annu Rev Cell Biol 4, 289-331.

Ghovvati S, Nassiri MR, Mirhoseini SZ, Moussavi, AH, and Javadmanech A (2009) Fraud identification in industrial meat products by multiplex PCR assay. Food Control 20, 696-9.

Girish PS, Anjaneyulu ASR, Viswas KN, Anand M, Rajkumar N, and Shivakumar BM (2004) Sequence analysis of mitochondrial 12S rRNA gene can identify meat species. Meat Sci 66, 551-6.

Haunshi S, Basumatary R, Girish PS, Doley S, Bardoloi RK, and Kumar A (2009) Identification of chicken, duck, pigeon and pig meat by speciesspecific markers of mitochondrial origin. Meat Sci 83, 454-9.

Jonker KM, Tilburg JJHC, Hägele GH, and De Boer E (2008) Species identification in meat products using real-time PCR. Food Addit Contam: Part A 25, 527-33.

Kim KH, Kim YS, Kim MR, Lee HY, Jung YK, Lee JH et al. (2014) Development of species-specific primer to determine the authenticity of vegetable raw materials in food. Food Eng Prog 18, 419-26.

Koh BRD, Kim JY, Na HM, Park SD, and Kim YH (2011) Development of species-specific multiplex PCR assays of mitochondrial 12S rRNA and 16S rRNA for the identification of animal species. Kor $J$ Vet Serv 34, 417-28.

Li J, Hong Y, Kim JH, Qin P, Kim M, and Kim HY (2015) Multiplex-PCR for simultaneous identification of turkey, ostrich, chicken, and duck. $J$ Korean Soc Appl Biol Chem, 58, 887-93.

Park YC, Jung YH, Kim MR, Shin JH, Kim KH, Lee JH et al. (2013) Development of detection method for Niphon spinosus, Epinephelus bruneus, and Epinephelus septemfasciatus using 16S rRNA gene. Kor $J$ Food Sci Technol 45, 1-7.

Safdar M and Junejo Y (2015) A multiplex-conventional PCR assay for bovine, ovine, caprine and fish species identification in feedstuffs: Highly sensitive and specific. Food Control 50, 190-4.

Walker JA, Hughes DA, Hedges DJ, Anders BA, Laborde ME, Shewale J et al. (2004) Quantitative PCR for DNA identification based on genomespecific interspersed repetitive elements. Genomics 83, 518-27.

Yang L, Tan Z, Wang D, Xue, L, Guan MX, Huang T et al. (2014) Species identification through mitochondrial rRNA genetic analysis. Sci Reports 4, 4089, doi: 10.1038/srep04089.

You J, Huang L, Zhuang J, and Mou Z (2014) Species-specific multiplex realtime PCR assay for identification of deer and common domestic animals. Food Sci Biotechnol 23, 133-9. 